\title{
Un aporte a las epistemologías del Sur
}

\author{
Alejandra M. Gordillo \\ Miembro del Comité Editorial de REVCOM
}

Nos complace presentar esta nueva edición de REVCOM que tiene como tema central la planificación y comunicación estratégica. En el Dossier temático, los artículos de nuestros destacados invitados nos introducen en un universo de posibilidades de intervención y de participación en procesos comunicacionales donde prima el encuentro con la diversidad, el diálogo intercultural y la apertura a conocer e interpretar al otro a partir de sus propios universos de significación y sentidos.

Esta perspectiva de abordaje de lo comunicacional como encuentro en la diversidad adquiere gran relevancia en nuestro contexto nacional y latinoamericano porque germina justamente en Argentina, en la Universidad Nacional de Rosario, a partir de la tesis doctoral de Sandra Massoni (2003) y los sucesivos aportes de docentes, investigadores y profesionales que aplicaron la metodología de la investigación-acción enactiva a procesos comunicacionales anclados en espacios de encuentro socio cultural. Una apuesta por conocer, planificar y actuar que supone una apertura epistemológica: abre las puertas a otros saberes, a conocimientos adquiridos en las prácticas cotidianas de sujetos y grupos que han demostrado su eficiencia y su eficacia y que no han sido necesariamente atravesadas por el conocimiento científico, pero que no por ello son menos válidas.

Constituye entonces una auténtica manera de pensar en espacios de aprendizaje específicos, situados en un tiempo y un espacio concretos. Ejecutar estas prácticas de Comunicación Estratégica nos interpela porque implica una concepción que rompe los estereotipos y las recetas teóricas y metodológicas academicistas. Es un modelo que en cambio nos propone asumir el valor de lo dialógico para poder encontrarnos con la otredad, para lograr el encuentro y la comunión de la auténtica comunicación. Sólo así se podrán comprender los sentidos que aquellas prácticas adquieren en esos contextos. Es una propuesta de descubrir los universos simbólicos y de construir nexos, rompiendo moldes de racionalidad previos y elaborando en cada intervención una nueva matriz. 
REVCOM | ISSN 2451-7836 | Año 4, \#8 | mayo de 2019 | Editorial | e001

Los artículos que compartimos en este Dossier nos permiten reflexionar juntos sobre comunicación estratégica y planificación en un universo de complejidades. No creo que haya sido azaroso que este modelo se concibiera en Argentina y esté expandiéndose hacia otras latitudes, pero sobre todo en América Latina. Es la muestra de la emergencia de un nuevo aporte a las epistemologías del Sur, entre cuyos objetivos -como expresa Boaventura de Sousa Santos- está identificar y valorizar lo que a menudo ni siquiera aparece como conocimiento a la luz de las epistemologías dominantes. Aquello que surge como parte de las luchas de resistencia contra la opresión y contra el conocimiento que legitiman esa opresión. La metodología de investigación enactiva que postula este modelo permite conocer formas de conocimiento empíricos, recuperar experiencias vitales que superan -sin desestimar sus grandes contribuciones- las abstracciones y la rigidez de los saberes adquiridos. Son una apuesta a asumir la fluidez de los procesos socio-históricos y comunicacionales.

Agradecemos a Sandra Massoni, Washington Uranga, Analía Chiavazza y Romina Trincheri por habernos compartido sus saberes y sus experiencias en la aplicación de este modelo. También en la sección Contribuciones, producto convocatoria permanente a la presentación de artículos para REVCOM, las lectores y los lectores encontrarán otros trabajos sobre comunicación estratégica, junto con otros temas, problemas y abordajes que como siempre expresan la diversidad y la potencialidad de los interrogantes sobre lo comunicacional.

Esperamos que estas lecturas disparen inquietudes e intereses para seguir construyendo juntos un corpus teórico que dé cuenta de nuestros aportes latinoamericanos al nutrido campo de la Comunicación Social.

http://perio.un/p.edu.ar/ojs/index.php/revcom/ Esta obra está bajo una Licencia Creative Commons Atribución-NoComercial-SinDerivar 4.0 Internacional 